\title{
COMPETIÇÃO DE CARNEIRO HIDRÁULICO DA FACULDADE DE TECNOLOGIA DE ALAGOAS COMO FERRAMENTA PRÁTICA DE APRENDIZAGEM DA DISCIPLINA DE HIDROLOGIA
}

\author{
Josemildo Verçosa de Araújo Júnior1, Romário Guimarães Verçosa de Araújo2, Renilda Correia de \\ Oliveira', Salmir Kleyton Barros Noia', Cezar Antônio Lima do Nascimento', Maria Eduarda da Silva', \\ Matheus Bruno da Silva', Isabelly Catharyne Eugênio dos Santos', Ruan dos Santos Rocha Nascimento', \\ Clayton dos Santos Silva ${ }^{3}$
}

\begin{abstract}
1Faculdade de Tecnologia de Alagoas, FAT, Maceió-AL, josemildo_j@hotmail.com; renildacorreia@fat-al.edu.br; salmirnoia@hotmail. com; cezar_antonio1@yahoo.com.br; eduarda.eng.99@gmail.com; matheus.bruno.ds@hotmail.com; isabelly.catharyne@hotmail.com; ruan1452@gmail.com

²Laboratório de Ecologia e Comportamento de Insetos, CECA, UFAL, Maceió-AL, romariorgva@hotmail.com

${ }^{3}$ Laboratório de Microbiologia, CECA, UFAL, Maceió-AL, clayton@live.com.pt
\end{abstract}

RESUMO: O carneiro hidráulico é uma ferramenta simples para bombeamento de água que utiliza como fonte para seu funcionamento energia limpa e renovável, é amplamente empregado em muitos locais onde a energia elétrica é escassa ou inexistente. Ultimamente nos cursos de engenharia vem se buscando métodos de aprendizagem mais significativos que promovam a autonomia dos alunos, despertando o interesse dos mesmos em aprender e aplicar os conceitos teóricos aprendidos em sala de aula, dessa forma objetivouse por meio desse trabalho realizar uma competição com os alunos de engenharia civil da FAT, durante a III Semana Acadêmica de Engenharia da instituição, os carneiros hidráulicos foram confeccionados de forma artesanal pelas equipes do $6^{\circ}$ período, utilizando apenas materiais previstos no regulamento, foi levado em consideração como critério de avaliação a funcionalidade correta do equipamento, vazão, relação volume inicial de água, volume bombeado e estética, as equipes tiveram 20 minutos para demonstrar 0 funcionamento do equipamento. Os melhores resultados foram obtidos para um caudal de elevação igual a 2,2 L/min, com aproximadamente 60 batidas por minuto. Foi possível verificar com essa competição os alunos ficaram motivados e promoveram sua autonomia, sendo aplicado os conceitos teóricos passados em sala de aula para uma aplicação prática.

Palavras-chave: bomba de ariete; energia limpa; aula prática; competição.

\section{COMPETITION OF HYDRAULIC RAM OF THE FACULTY OF TECHNOLOGY OF ALAGOAS AS A PRACTICAL LEARNING TOOL OF THE DISCIPLINE OF HYDROLOGY}

\begin{abstract}
Hydraulic ram is a simple tool for pumping water that uses as a source for its clean and renewable energy, is widely used in many places where electricity is scarce or nonexistent. Recently in the engineering courses one has been looking for more significant learning methods that promote the autonomy of the students, arousing their interest in learning and applying the theoretical concepts learned in the classroom, in order to achieve a competition with FAT civil engineering students, during the III Academic Engineering Week of the institution, the hydraulic sheep were handcrafted by the teams of the 6th period, using only materials provided for in the regulation, was taken into account as an evaluation criterion correct functionality of the equipment, flow, initial volume ratio of water, pumped volume and aesthetics, the teams had 20 minutes to demonstrate the equipment operation. The best results were obtained for an elevation flow equal to $2.2 \mathrm{~L} / \mathrm{min}$, with approximately 60 beats per minute. It was possible to verify with this competition the students were motivated and promoted their autonomy, being applied the theoretical concepts passed in the classroom for a practical application.
\end{abstract}

Keywords: water pump; clean energy; practical class; competition. 


\section{INTRODUÇÃO}

Para o bom funcionamento de uma propriedade rural o abastecimento de água é de fundamental importância, dessa forma são necessários equipamentos que elevem a água e a distribua. Um desses equipamentos que fazem a distribuição de forma eficiente e com baixo custo de implantação e manutenção é o carneiro hidráulico, se tornando viável em propriedades afastadas das fontes (PEIXOTO et al., 2015).

O carneiro hidráulico ou bomba de aríete é uma ferramenta simples de bombeamento de água que possui características geratriz e operatriz (MACINTYRE, 1980). A fonte de energia é a altura de queda d'água que, em geral, é produzida artificialmente por meio de pequena barragem. 0 bombeamento de água utilizando carneiro hidráulico é amplamente empregado em muitas locais, principalmente onde a energia elétrica é escassa ou inexistente (ABATE, BOTREL, 2002).

A recente crise de energia, tem ocasionado a exploração de fontes alternativas e limpas de energias para suprir o uso doméstico, indústria eagrícola ( $\mathrm{BHOl}$ et al., 1994). Entre as vantagens da utilização do carneiro hidráulico é a não necessidade de fontes externas de energia, tais como os combustíveis derivados de petróleo ou energia elétrica, a manutenção e a operação simples, não exigindo mão-de-obra qualificada, o custo de aquisição e/ou montagem relativamente baixos e a possibilidade de uso durante $24 \mathrm{~h}$ por dia recalcando água sem emissão de poluentes ou gases (CARACOL et al., 2007).

O sistema de bombeamento por carneiro consiste em um tanque elevado de alimentação, a tubulação de alimentação, o carneiro com as válvulas de escape e recalque, a câmara de ar, e

a tubulação de recalque. A função da câmara de ar é armazenar água na pressão de recalque entre golpes e absorver o choque do bombeamento.

A adoção de carneiros hidráulicos de modelo artesanal tem sido utilizada em algumas regiões do país, utilizando as águas de açudes para irrigar plantações. Os modelos de carneiros hidráulicos existente no mercado, principalmente para irrigação, como o industrial, apesar de suas vantagens, são feitos de metal fazendo com que a água não seja apropriada para o consumo humano, pois enferruja, sendo 0 modelo artesanal de PVC o mais indicado.
Conforme Abate \& Botrel (2002), o carneiro hidráulico é constituído por partes fixas e móveis. As partes fixas são: base, campânula e castelo. As partes móveis são: válvula de escape que é constituída de liga apropriada com longa duração e a válvula de recalque, revestida de couro ou de borracha.

Ultimamente vem se buscando métodos de aprendizagem mais significativos que promovam a autonomia dos alunos, despertando 0 interesse dos mesmos em aprender. As atividades práticas e participativas podem atuar como aliadas no momento do ensino de disciplinas profissionalizantes e torná-las mais compreensíveis.

Dessa forma objetivou-se com esse trabalho a competição entre os discentes do curso de engenharia civil, o desenvolvimento de um projeto de carneiro hidráulico associando a teoria passada em sala de aula na disciplina de hidráulica com a prática.

\section{MATERIAL E MÉTODOS}

A competição foi realizada com os alunos dos sextos períodos do curso de Engenharia Civil da Faculdade de Tecnologia de Alagoas, porém outros alunos do curso de Engenharia Civil e Engenharia de Produção da referida instituição participaram, sendo a confecção do carneiro hidráulico realizado pelos integrantes das equipes.

Tabela 1. Peças que foram permitidas de ser utilizadas para a confecção do carneiro hidráulico.

\begin{tabular}{lc}
\hline Peça & Quantidade \\
\hline Ts de 1 polegada & 2 \\
Niples de 1 polegada & 3 \\
Válvula de retenção vertical de 1 polegada & 1 \\
Válvula de poço de 1 polegada & 1 \\
Bucha de redução de 1 polegada para $3 / 4$ de & 1 \\
polegada & \\
Adaptador para mangueira de $3 / 4$ para $1 / 2$ de & 1 \\
polegada & 1 \\
Parafuso com duas porcas & 1 \\
Mola & 1 \\
Fita veda rosca & 1 \\
Cola para cano & 1 \\
Garrafa PET de 2 litros ou cano com tampa & \\
\hline
\end{tabular}

As recomendações para confecção do carneiro hidráulico para as equipes foram descritas em edital do torneio. E podem ser observadas na Figura 1, onde: tampa 
da garrafa ou cano com tampa (A); bucha de redução de uma polegada por $3 / 4$ polegada (B); tê de uma polegada (C); bucha de PVC branco de uma polegada (D); adaptador para mangueira $(E)$; cano de aço de $3 / 4$ de polegada $(P)$; niple de uma polegada $(\mathrm{F})$; niple galvanizado $(\mathrm{J})$; válvula de poço ou de impulso (L); encaixe do parafuso 5/16 ou M8 (M); mola, entre a arruela e o tampão da válvula (N); os outros dois niples foram utilizados, sendo um rosqueado à bucha de redução de duas polegadas $(G)$; fixando nesta peça a válvula de retenção vertical $(H)$; em outro niple encaixou-se o tê galvanizado de duas polegadas (K); em uma de suas saídas foi colocado o cano de aço de duas polegadas de diâmetro (0). Esse tubo de alimentação foi instalado a 30 centímetros abaixo do nível da água para evitar sucção de ar e com desnível mínimo de 1,5 metro para que a água fosse conduzida até 0 carneiro. Para impedir que o entupimento do cano, foi colocado um pedaço de tela de sombreamento na entrada com arame, as recomendações de montagem do carneiro hidráulico.

Os carneiros hidráulicos foram apresentados na competição durante a III Semana Acadêmica de Engenharia da instituição. Onde foi realizado a demonstração de funcionamento da bomba, qual foi avaliado por uma banca de três professores.

$\mathrm{Na}$ unidade do Barro Duro da FAT foi posicionado no térreo do bloco $\mathrm{A}$ um reservatório onde foram acoplados os carneiros hidráulicos. Outro reservatório foi posicionado no primeiro andar com uma fita métrica para aferir o nível da água. Cada grupo indicou ao menos dois de seus membros para acompanhar o teste de funcionamento do carneiro hidráulico. As equipes tiveram até 20 minutos para demostrar o funcionamento do carneiro hidráulico.

Figura 1. Esquema de montagem do carneiro hidráulico artesanal. (Foto: EFAORI, 2012)

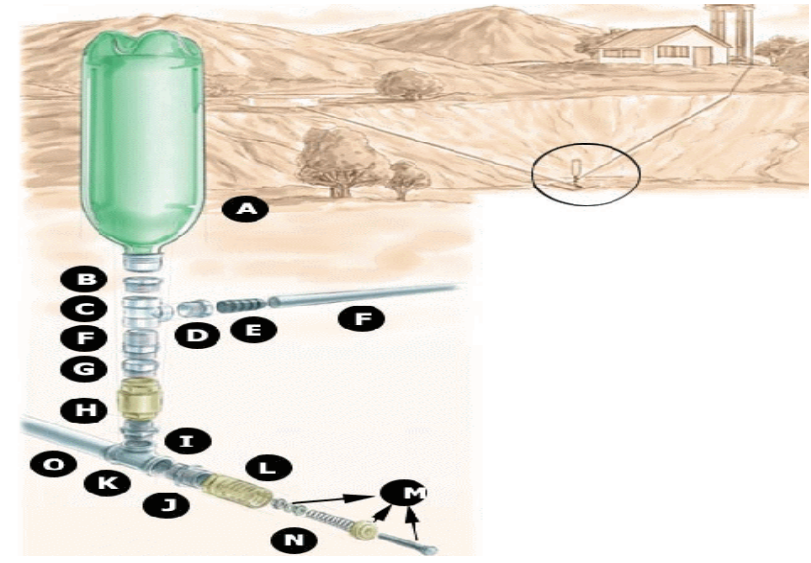

Foram tomados como parâmetros para avaliação das equipes a funcionalidade correta do carneiro hidráulico, vazão e relação volume inicial de água, volume bombeado e estética do carneiro hidráulico.

\section{RESULTADOS E DISCUSSÃO}

A primeira atividade a ser desenvolvida na III Semana Acadêmica das Engenharias foi a construção dos carneiros hidráulicos, em seguida deu início a competição com a demonstração de funcionalidade no dia 08 de outubro de 2018 no laboratório de Hidráulica da FAT-AL. O carneiro hidráulico foi testado para um desnível (constante) de 1,0 m entre a fonte de alimentação que era um reservatório de 20 litros adaptado para execução do trabalho e a bomba de ariete, e para uma altura de elevação de aproximadamente 5 metros. Os trabalhos foram classificados de acordo com a funcionalidade, maior vazão e estítica da bomba. Os melhores resultados foram obtidos para um caudal de elevação igual a 2,2 L/ min, com aproximadamente 60 batidas por minuto.

As equipes vencedoras da competição foram premiadas com brindes fornecidos pela FAT-AL (Figura 2), essa premiação foi fornecida para as equipes que ficaram na primeira e segunda colocação obedecendo os critérios avaliativos do torneio.

Conforme Soczek (2016), esses recursos didáticos contribuem para que haja a motivação nos alunos para estudarem, tornar o ensino mais interessante; facilitar a aprendizagem, desenvolver o raciocínio lógico, propiciar a socialização e a prática de experimentações contribuem a um processo de ensino mais esclarecedor. Este conjunto de fatores faz parte do que se propõe a uma avaliação diária e somativa.

Figura 2. Equipe vencedora do noturno do II torneio do carneiro hidráulico da FAT-AL recebendo premiação. (Foto: Autores, 2018)

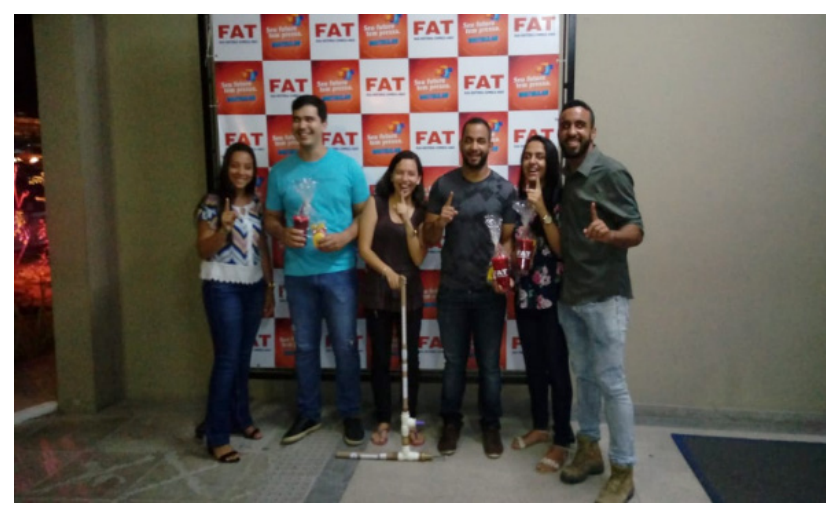


Foi possível repassar para os alunos a importância da utilização de energia renováve para diminuir os impactos ambientais. De acordo com Goldemberg et al. (2007) é preciso estimular a utilização de energia limpa no Brasil, pois os padrões atuais baseados nas fontes fósseis geram emissões de poluentes locais, gases de efeito estufa e põem em risco o suprimento de longo prazo do planeta.

O estímulo à construção do próprio conhecimento, fazendo o aluno sentir-se um elemento integrante, ativo e responsável pela aprendizagem, induz a reflexão e exploração das suas próprias capacidades, representa um importante desafio produtivo para esses alunos. As estratégias que os alunos identificam com potencial de motivação são: assiduidade do professor, aulas dinâmicas, realização de trabalhos práticos, clareza na apresentação dos conteúdos e professores que clarifiquem as dúvidas (MONTEIRO et al., 2010).

O carneiro hidráulico de PVC tem feito bastante sucesso, visto que integrantes das equipes tem instalado com sucesso em suas propriedades e sítios de familiares. Os alunos têm mencionado que a confecção da bomba é simples, seu funcionamento utiliza apenas a força da gravidade, não usa energia elétrica e nem combustível e fica bem mais barato que o carneiro industrial feito de ferro. A água bombeada por ele é usada para irrigação e no abastecimento do cocho dos animais, além de abastecimento em sítios onde não possui sistema de abastecimento da companhia local.

A confecção desse equipamento possibilitou na competição e foi observado em sala de aula o entendimento dos alunos sobre os conceitos teóricos por meio de observações reais dos conceitos físicos aplicados. Os alunos demonstraram conhecimentos e habilidades adquiridos durante a execução da prática, favorecendo também o nível motivacional durante o trabalho.
Figura 3. Carneiro hidráulico artesanal instalado na propriedade de um aluno que participou da atividade prática. (Foto: Autores, 2018)

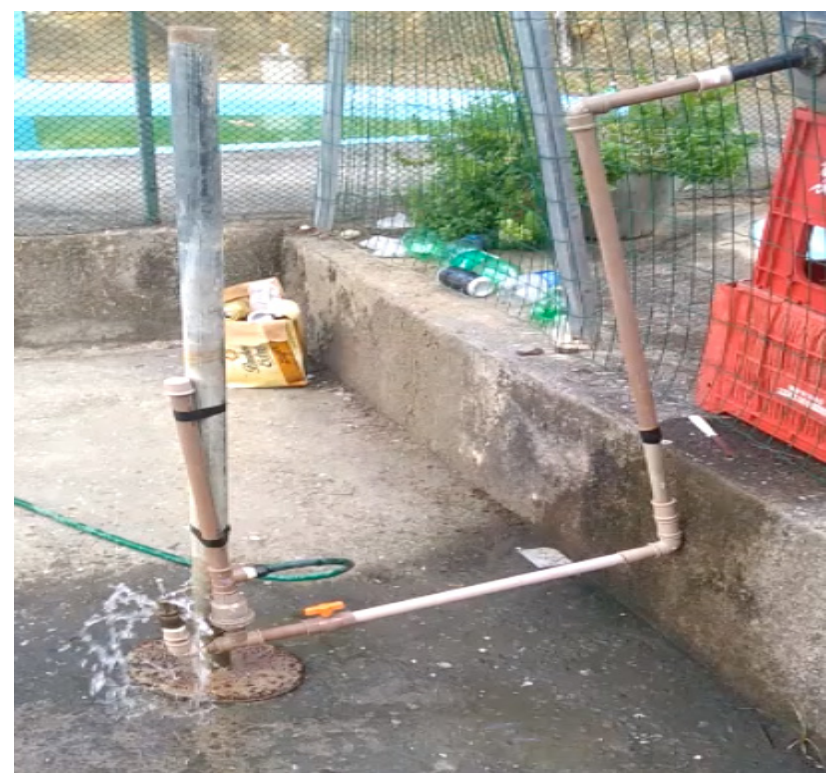

\section{CONCLUSÕES}

A avaliação foi bastante positiva tendo em vista que com essa competição os alunos ficaram motivados e promoveram sua autonomia, sendo aplicado os conceitos teóricos da disciplina de hidráulica passados em sala de aula.

\section{REFERÊNCIAS}

ABATEL, C.; BOTREL, T. A. Carneiro hidráulico com tubulação de alimentação em aço galvanizado e em PVC. Scientia Agrícola, 2002, 59, 197-203.

BHOI, K. L.; RAM S.; CHAUHAN, H. S. Field evaluation of hydraulic rams. ICID Bulletin, 1994, 43, 105-116.

CARACOL, D. C.; DAMASCENO, F. A.; GRIFFANTE, G.; ALVARENGA, L. A. Características construtivas de um carneiro hidráulico com materiais alternativos. Revista Brasileira Engenharia Agrícola Ambiental, 2007, 11, 349-354.

Escola Família Agrícola do Orizona: Curso técnico em agropecuária de nível média. Carneiro hidráulico. Disponível em: http://efaorizona.blogspot.com/2012/04/ como-fazer-um-carneiro-hidraulico.html. Acesso: 18 de outubro de 2018. 
GOLDEMBERG, J. LUCON, O. Energia e meio ambiente no Brasil. Estudos Avançados, 2007. 21, 7-20.

MACINTYRE, A. J. Bombas e instalações de bombeamento. $2^{\mathrm{a}}$ ed. Rio de Janeiro: Guanabara Dois, 1980.

MONTEIRO, S.; ALMEIDA, L. S.; CRUZ, J. F. A.; VASCONCELOS, M. Percepções de alunos de excelência relativamente ao papel dos professores: um estudo com alunos de engenharia. Revista Portuguesa de Educação, 2018, 32, 213-238.
PEIXOTO, H. D.; LUCHESE, T. C. Estudo sistemático do carneiro hidráulico: Uma avaliação da dependência entre volume recalcado e os parâmetros da construção do equipamento. Anais do V SEPE \& V Jornada de Iniciação Científica, v. 15, 2015.

SOCZEK, M. L. O carneiro hidráulico como elemento motivador ao estudo de hidrodinâmica. Cadernos PDE, v. 1, 2016. 25p. 